\title{
Polyamines as anabolic growth regulators revealed by transcriptome analysis and metabolite profiles of tomato fruits engineered to accumulate spermidine and spermine
}

\author{
Alka Srivastava ${ }^{1}$, Sang Ho Chung ${ }^{2, a}$, Tahira Fatima ${ }^{2,3}$, Tatsiana Datsenka ${ }^{1}$, \\ Avtar K. Handa ${ }^{1, *}$, Autar K. Mattoo ${ }^{2, *}$ \\ ${ }^{1}$ Department of Horticulture, Purdue University, W. Lafayette, IN 47906, USA; ${ }^{2}$ USDAARS, Henry A. Wallace \\ Beltsville Agricultural Research Center, Bldg. 001, Beltsville, MD 20705-2350, USA; ${ }^{3}$ University of Maryland, College \\ Park, MD 20742, USA \\ *E-mail: mattooa@ba.ars.usda.gov, ahanda@purdue.edu
}

Received November 7, 2006; accepted January 15, 2007 (Edited by K. Hiratsuka)

\begin{abstract}
Transgenic tomato (Solanum lycopersicum) genotypes that were engineered to contain high endogenous polyamines levels in fruit due to a ripening targeted expression of yeast SAM decarboxylase were used as a model system to determine the effects of enhanced spermidine (Spd) and spermine (Spm) on gene expression. Subtractive cloning of total RNA of transgenic from wild type ripening fruits resulted in isolation of several genes that were up-regulated and represented a wide range of functional classifications. To establish the global pattern of gene expression in transgenic and wild-type fruit, a custom array containing 1066 unique fruit cDNA was constructed and used to quantify levels of a large number of transcripts in transgenic and wild-type fruits during the ripening. About one-quarter of genes on the array were differentially regulated in transgenic compared to wild type fruits. The differentially up-regulated genes were twice as abundant as down-regulated genes in the high polyamine fruits. The differentially expressed genes represented functional categories including transcription, translation, signal transduction, chaperone family, stress related, amino acid biosynthesis, ethylene biosynthesis and action, polyamine biosynthesis, isoprenoid pathway, and flavonoid biosynthesis. About 44\% of the differentially regulated cDNAs included genes encoding products not yet classified for the functional attributes. Based on the results presented here on the limited transcriptome in conjunction with metabolite profiles showing significant enhancement of anabolic pathways in transgenic fruits, we propose that $\mathrm{Spd} / \mathrm{Spm}$ act as anabolic growth regulator.
\end{abstract}

Key words: Fruit ripening, gene expression, plant metabolism, polyamines, Solanum lycopersicum.

Plant growth regulators including the five classic hormones, namely, auxins, cytokinins, gibberellins, abscisic acids and ethylene are known to influence plant development in general and floral development, fruit set, fruit ripening and senescence in particular (Ross and O’Neill 2001; Srivastava and Handa 2005). Other growth regulators such as brassinosteroids, jasmonic acid, salicylic acid and polyamines are becoming known as signaling molecules in diverse plant processes (Walden et al. 1997; Mattoo and Handa 2004). Much of the earlier data with plant growth regulators was of pharmacological nature but recent biochemical, genetic and molecular analyses are beginning to reveal the molecular mode of hormonal regulation of plant metabolism including fruit development and ripening (Giovannoni 2004; Mattoo and Handa 2004; Srivastava and Handa 2005). Polyamines (PAs) are ubiquitous, low molecular weight polycations that have been implicated in a number of physiological and developmental processes in various organisms (Galston and Sawhney 1990; Cohen 1998; Cassol and Mattoo 2003). The most commonly occurring PAs include the diamine, putrescine (Put), triamine spermidine (Spd), and tetraamine spermine (Spm). The diamine Put is synthesized from basic amino acids, arginine or ornithine by the action of enzymes arginine decarboxylase or ornithine decarboxylase, respectively (Cohen 1998). Both Spm and Spd are synthesized by sequential addition to Put of an aminopropyl moiety, provided by decarboxylated S-adenosylmethionine (SAM). The enzyme, Sadenosylmethionine decarboxylase (SAMdc; EC 4.1.1.50), catalyzes the synthesis of decarboxylated SAM from SAM and is a key step in the regulation of polyamines (Cohen 1998; Cassol and Mattoo 2003). PAs are important for fruit development but have also been implicated as antisenescence factors; in context of fruit,

${ }^{a}$ Present address: Department of Microbiology, Mokwon University, Doan-dong 800, Seo-ku, Taejon 302-729, Republic of Korea Abbreviations: EST, Expressed Sequence Tag; PA, Polyamines; SAMdc, S-adenosylmethionine decarboxylase; Spd, spermidine; Spm, spermine. 
the latter is exhibited as delayed ripening responses (Egea-Cortinez and Mizrahi 1991; Cassol and Mattoo 2003).

The fact that PAs and ethylene share SAM as a common precursor in their biosynthesis pathways, prompted investigations to check if the two pathways compete for this intermediate (Fluhr and Mattoo 1996) and if a cross talk exists between PAs and ethylene to regulate fruit ripening (reviewed in Cassol and Mattoo 2003). Cross-talks, both complementary and antagonistic in nature, are suggested to be the possible modes of interactive regulation by hormones exerted during developmental stages of fruit (Ozga and Reinecke 2003; Mattoo and Handa 2004; Srivastava and Handa 2005). In view of the observations showing that polyamines have opposite effects of ethylene, the possible adjustment of their endogenous levels by expression of heterologous genes in favor of higher levels of PAs, the antisenescence agents, has been attempted with varying results (Hamill et al. 1990; DeScenzo and Minocha 1993; Noh and Minocha 1994; Kumar et al. 1996; Watson and Malmberg 1998; Pedros et al. 1999; Mehta et al. 2002; Kasukabe et al. 2004). Whereas initial studies involving heterologous expression of various genes involved in PA biosynthesis demonstrated the possibility of manipulating Put flux and accumulation (Hamill et al. 1990; DeScenzo and Minocha 1993; Noh and Minocha 1994), later studies with sense and antisense expression of such genes revealed varying phenotypes and physiological responses. For example, potato transgenic lines expressing tissue specific SAMdc showed smaller sized tubers (Kumar et al. 1996; Pedros et al. 1999). Heterologous, constitutive expression of Spd synthase in Arabidopsis enhanced the expression of stress-related genes and led to increased tolerance to several environmental stresses (Kasukabe et al. 2004). However, fruit-specific expression of the yeast SAMdc in transgenic tomatoes exhibited fruits with improved juice quality and delayed ripening on the vine (Mehta et al. 2002). Surprisingly, ethylene synthesis increased considerably (Mehta et al. 2002). These data showed that the biosynthesis of PAs and ethylene could occur simultaneously, raising further questions about the existence of a cross talk between these two signaling molecules. Metabolite profiles of tomato fruit accumulating higher PAs, Spd and Spm, suggested that $\mathrm{Spd} / \mathrm{Spm}$ are sensed as organic nitrogen by the ripening fruit cells, which leads to the accumulation of specific metabolites (Mattoo et al. 2006). These results suggest that PAs initiate anabolic and nitrogen-carbon interactions.

Regulating endogenous levels of PAs via molecular engineering provides an excellent genetic system to study the effects of PAs on gene expression and thereby explore the possible mode of their regulation on various physiological aspects. Using cDNA microarrays, Kasukabe et al. (2004) have shown that many stressrelated genes are up-regulated in a transgenic line of Arabidopsis over-expressing Spd synthase when grown at $5^{\circ} \mathrm{C}$. Fruits over-accumulating $\mathrm{Spd}$ and $\mathrm{Spm}$ with minimum accumulation of Put during ripening (Mehta et al. 2002; Mattoo et al. 2006) provided us a model system to define alterations at the transcriptome level and effects of $\mathrm{Spd} / \mathrm{Spm}$ on the metabolome. The information thus generated has enabled synthesis of information about $\mathrm{Spd} / \mathrm{Spm}$-mediated coordination between different levels of regulation that may eventually impact nutritional attributes and stress response of the tomato fruit.

\section{Materials and methods}

\section{Plant material}

Wild type, control tomato plants (Solanum lycopersicum L.) cv. Ohio 8245 and its isogenic transgenic lines $(556 \mathrm{HO}$ and $579 \mathrm{HO}$ ) homozygous for the introduced ySAMdc (Mehta et al. 2002) were grown in the green house under conditions previously described (Biggs et al. 1986). For ripening stages, fruits were tagged at the breaker (BR) stage and harvested at early ripening (BR and $\mathrm{BR}+3$ days) and late ripening stages $(\mathrm{BR}+7$ days and $\mathrm{BR}+15$ days). Also included were pericarps from green (GR) fruit development stage (25 days after pollination and the mature green stage when the fruit has acquired maximal size) from both the wild type and transgenics.

\section{cDNA subtractive cloning}

Total RNA was isolated from the transgenic $556 \mathrm{HO}$ and $579 \mathrm{HO}$ lines and the wild type/azygous lines (Mehta et al. 2002), as described previously ( $\mathrm{Li}$ et al. 1992). To clone the genes differentially expressed between transgenic plants and non-transgenic plants, cDNA subtraction was performed using PCR-Select ${ }^{\mathrm{TM}}$ cDNA subtraction kit and SMART $^{\mathrm{TM}}$ PCR cDNA synthesis kit (Clontech). All the procedures were done essentially as described in the manufacturer's manual. Briefly, first-strand cDNA for the tester and driver was synthesized from total RNA $(10 \mu \mathrm{g})$ with $\mathrm{MMLV}$ reverse transcriptase (Superscript II, Gibco BRL) at $42^{\circ} \mathrm{C}$ for $1 \mathrm{~h}$. Double-stranded cDNA was synthesized by long-distance PCR using the Advantage 2 PCR kit in a Perkin-Elmer Thermal Cycler. Tester and driver cDNAs were separately digested with a restriction enzyme RsaI to obtain shorter and blunt-ended molecules. Two tester populations were made with different adaptors (Adaptor 1 and Adaptor 2R) but driver cDNA had no adaptors. After first hybridization to equalize and enrich the differentially expressed sequences and second hybridization to generate the templates for PCR amplification of differentially expressed sequences, the differentially expressed sequences were amplified through first PCR and second PCR with specific nested primers. The subtracted cDNAs were then cloned into the TOPO TA cloning vector (Invitrogen). All the cloned sequences were determined by DNA sequencing at University of Maryland and compared with the genes in the Genbank database using a BLAST program from NCBI. 


\section{Construction of normalized cDNA library and sequence analysis}

Fruits at the turning stage from Heinz breeding lines 70620 and 70320 were used for total RNA isolation (Ramakrishna et al. 2003). cDNA synthesis and normalization were carried out by a modification of a previously published method (Takahashi et al. 1994). Briefly, first cDNA strand was synthesized using $1 \mu \mathrm{g}$ of NotI primer (5'-CAATTCGCGGCCGCTTTTTTTTTTTTTTTTT- $3^{\prime}$ ) and 200U of Superscript II RNase $\mathrm{H}^{-}$reverse transcriptase (Gibco BRL, USA) in a $20 \mu \mathrm{l}$ reaction mixture following the manufacturer's instruction. Twenty microliters of first strand cDNA reaction mixture were used for the second strand cDNA synthesis following the Clonetech cDNA select subtraction kit method. The blunt ended double stranded cDNA was ligated to $2 \mu \mathrm{g}$ of phosphorylated lone linker (5'-GAGATATTACCTGCAGGTACTC-3' and 3'-TATAATGGACGTCCATGAG-5') and then amplified using LLSse8387IA primer (5' GAGATATTACCTGCAGGTACTC-3') in a thermal cycler (Perkin Elmer, Cetus) for 25 cycles at $94^{\circ} \mathrm{C}$ for $2 \mathrm{~min}, 50^{\circ} \mathrm{C}$ for $2 \mathrm{~min}$ and $72^{\circ} \mathrm{C}$ for $4 \mathrm{~min}$. For generating a normalized cDNA library, equal amounts of amplified cDNA from lines 70620 and 70320 were mixed and referred to as the straight (S) cDNA mix. Three successive equalization cycles (EC) were carried out as described (Takahashi et al. 1994). For the first EC, 1.5 $\mu \mathrm{g}$ of pooled cDNAs were dissolved in re-association buffer [0.3 M sodium phosphate, $\mathrm{pH} 7.0,0.4 \mathrm{mM}$ EDTA and $0.04 \%$ SDS], denatured by boiling for $5 \mathrm{~min}$ and kept at $65^{\circ} \mathrm{C}$ for $6 \mathrm{~h}$ for re-association. Separation of single stranded (ssDNA) and double stranded cDNAs was achieved using a water-jacketed hydoxyapatite (HPT grade, Biorad, USA) column maintained at $60^{\circ} \mathrm{C}$ (Sambrook et al. 1989). The ssDNA fraction was amplified by PCR with LLSse8387IA primer using the same conditions as above and the resulting double stranded cDNA was subjected to the second cycle of normalization to obtain Equalization-II cDNA. Equalization-III cDNA mixture, obtained after third cycle of normalization of Equalization-II cDNA, was amplified and digested sequentially with NotI and Sse8387I, purified and ligated to PstI-and Not I-digested plasmid vector pBluescript SKII- (Stratagene, La Jolla, USA). The ligated DNA was electroporated into Escherichia coli DH5 $\alpha$ competent cells (Gibco BRL, USA). Over 5000 white colonies were randomly picked and grown in a 384-well plate containing LB broth and $50 \mu \mathrm{g} / \mathrm{ml}$ ampicillin. All colonies were printed in duplicate on nylon membranes using Biogrid II robotic workstation (Biorobotics, USA). Individual membranes were hybridized to ${ }^{32} \mathrm{P}$-labeled cDNA synthesized to total RNAs isolated from immature green, mature green, breaker, turning and red tomato fruits. Expressed Sequence Tags (ESTs) that exhibited signals significantly above the background were selected. The inserts from selected clones were sequenced using ABI prism 3700 sequencer at the Purdue University DNA Sequencing Facility. Vector sequences were removed and the edited sequences were compared with those present in the EST (dbEST), non-redundant nucleotide, and protein databases (Genbank) at the National Center for Biotechnology Information (NCBI). The cut-off e-value of $10^{-4}$ was used. Stackpackv2.2 (Electric Genetics PTY Ltd.) was used to analyze the consensus and unique sequences amongst the ESTs. All sequences were submitted to the public EST databases (accession number CN550588-CN550664 and CD002010-CD003544) at the NCBI.

\section{Construction of cDNA array}

A total of 1536 cDNA clones were amplified using T3 and T7 universal primers with the GeneAmp PCR system 9600 (Perkin Elmer, Foster city, CA). The PCR reaction mix contained $10 \mu 1$ of 10X PCR buffer [100 mM Tris- $\mathrm{HCl}, \mathrm{pH} 8.3 ; 500 \mathrm{mM} \mathrm{KCl}$ ], $2 \mu \mathrm{l}$ of Taq polymerase, $8 \mu \mathrm{l}$ of $25 \mathrm{mM} \mathrm{MgCl}_{2}, 2.5 \mu \mathrm{l}$ (325 ng) of each T3 and T7 primers and $5 \mu$ of the plasmid DNA with the final volume made to $100 \mu \mathrm{l}$ with sterile distilled water. The PCR cycles consisted of 1 cycle at $94^{\circ} \mathrm{C}$ for $2 \mathrm{~min}, 30$ cycles at $94^{\circ} \mathrm{C}$ for $30 \mathrm{~s}, 50^{\circ} \mathrm{C}$ for $30 \mathrm{~s}$ and $72^{\circ} \mathrm{C}$ for $1 \mathrm{~min}$, followed by an extension at $72^{\circ} \mathrm{C}$ for $5 \mathrm{~min}$. The PCR products were electrophoresed on $1 \%$ agarose gels and visualized. Nucleic acids were precipitated with $1 / 10$ th volume of $3 \mathrm{M}$ sodium acetate and 2.5 volumes of chilled ethanol, kept at $-20^{\circ} \mathrm{C}$ for 2 $\mathrm{h}$, then centrifuged at the maximum speed in Eppendorf centrifuge for $20 \mathrm{~min}$, air dried and resuspended in $14 \mu \mathrm{l}$ of $0.1 \mathrm{~N} \mathrm{NaOH}$ containing $0.01 \%$ Orange G dye. PCR products (2 $\mu 1$ each) of ESTs were combined, precipitated as above and resuspended in $50 \mu \mathrm{l}$ of the printing solution. A 2-fold dilution series was printed as a standard on the array (Yang et al. 2002). Positive controls were: housekeeping tomato ubiquitin, G3PDH, $\alpha$ and $\beta$ tubulin, and actin. The negative controls included the empty vector pBSKSII and ESTs from a pig cDNA (a gift from Dr. Diane Moody, Purdue University) that did not hybridize to tomato cDNAs. The total of $1536 \mathrm{cDNAs}$ including PCR amplified products, positive and negative controls and standard dilution series were transferred to 384well plate. All cDNAs were printed on PerForma II membranes (Genetix, USA) in duplicates using the 384 pin tool $(0.4 \mathrm{~mm}$ pin diameter) in the Biogrid II robotic workstation in a $3 \mathrm{X} 3$ format (Biorobotics, USA) at the Purdue Genomic Center.

\section{Macroarray hybridization}

Macroarray hybridization experiments were performed in duplicates with radiolabeled cDNA made to total RNA isolated in duplicate from all stages of the fruit tissues of transgenic and control lines. Total RNA ( $5 \mu \mathrm{g})$ from fruit pericarp of the wild type and transgenic lines was reverse transcribed using SuperscriptII reverse transcriptase (Invitrogen) and Oligo $(\mathrm{dT})_{12-18}$ as primer $(0.5 \mu \mathrm{g})$ in a reaction mixture containing $1 \mathrm{mM}$ each of dCTP, dTTP and dGTP along with $50 \mu \mathrm{Ci}$ of $\left[\propto{ }^{32} \mathrm{P}\right] \mathrm{dATP}$ following manufacturer's instructions. Unincorporated radioactive nucleotides were removed by passing the reaction mixture through G-50 Sephadex columns (Sambrook et al. 1989). The cDNA arrays were washed with pre-hybridization buffer $\left[0.25 \mathrm{M} \mathrm{NaHPO}_{4}, \mathrm{pH} 7.2,5 \mathrm{mM}\right.$ EDTA, $4 \%$ SDS, $1 \mathrm{X} \mathrm{SSC}$ ] at $62^{\circ} \mathrm{C}$ for $2 \mathrm{~h}$. Membranes were hybridized at $62^{\circ} \mathrm{C}$ for 18 to $24 \mathrm{~h}$ in a solution containing $0.5 \mathrm{M}$ NaHPO4, pH 7.2, $10 \mathrm{mM}$ EDTA, \% SDS and $1 \times 10^{6}$ to $4 \times 10^{-6} \mathrm{cpm} / \mathrm{ml}$ of probe. Filters were washed twice for $10 \mathrm{~min}$ each with $2 \mathrm{X}$ SSC and $0.1 \%$ SDS and exposed to phosphor screens (Molecular Dynamics, Sunnyvale, CA, USA) for $12 \mathrm{~h}$.

\section{Data acquisition and analysis}

The phosphor screens were scanned with the Typhoon Phosphorimager (Amersham Biosciences, Pistacaway, NJ) and the signal intensities were quantified using Imagene software 
(Biodiscovery). Predefined grids with defined circles were placed on each image and the spots were manually adjusted to ensure optimal spot recognition. The mean signal intensities and the mean background intensities generated by the software were exported into separate Excel spreadsheets. The local background was subtracted from each spot. For normalization of the signal, the signal intensity of each individual, background-corrected spot was divided with the median signal intensity value of the standards on each array. Each array had 384 empty spots as blank controls. The normalized signal intensity of a spot was considered detectable if it was above the 95th percentile of the background-corrected, normalized empty spots. If 3 out of the 4 replicate spots for a given EST showed signal intensity below normalized detectable limit, the EST was considered undetected. We examined 1522 ESTs excluding the 14 arrayed spots as internal standards. To identify genes differentially expressed in the transgenic fruits compared to the control wild type fruit, data from green, early ripening (BR and $\mathrm{BR}+3$ days) and late ripening $(\mathrm{BR}+7$ and $\mathrm{BR}+15$ days $)$ from the two genotypes were analyzed. The effects of increased Spd and Spm levels in $556 \mathrm{HO}$ and $579 \mathrm{HO}$ lines were examined at three stages of fruit ripening in an analysis of variance (ANOVA) modeling framework represented by the equation

$\mathrm{y}_{\mathrm{ijk}}=\mu+\mathrm{t}_{\mathrm{i}}+\mathrm{t}_{\mathrm{i}}(\omega)+\varepsilon_{\mathrm{ik}}$

in which $y$ is the intensity of the EST as measured on the ith genotype for the jth stage and kth replicate after correction for the local background signal and normalization. The parameter $\mu$ is the overall mean of the normalized values of that gene. Fixed effects for genotype $\left(\mathrm{t}_{\mathrm{j}}\right)$, where $i$ is genotype (ySAMDC transgenic or Ohio wild type cv 8245 line) and interaction between genotype and stage $\left[\mathrm{t}_{\mathrm{i}}(\omega)\right]$ (where stage indicates the tissue examined, namely the fruit tissues at green, early ripening and late ripening stage) were examined. The error $\left(\varepsilon_{\mathrm{kj}}\right)$ represents random variation for the ith genotype and the kth replicate $(j=1, \cdots, 8$ for fruit tissues). The null hypothesis that the gene's expression levels were not different between the transgenic and wild type control lines along with the interaction between the genotype and the stage was tested by performing $\mathrm{F}$ tests of the effect of the genotype on each gene and then calculating a $\mathrm{P}$ value for each gene. Also examined was the model for conformation to the assumption of normality of the residuals by testing the null hypothesis that the residuals for each gene were normally distributed. We used a Bonferroni significance level of $0.05 / 710$ or 0.0000704 as a criterion for rejecting the null hypothesis of significant stage effect (Benjamini and Hochberg 1995). We also applied a liberal threshold of 0.05 to account for the inverse relation between type I (false positives) and type II (false negatives) errors as well as the over conservativeness of Bonferroni corrections (Singh et al. 2003). In order to select for significant ESTs, we color coded ESTs showing P values less than 0.05 but greater than the Bonferroni correction (0.0000704) and the $\mathrm{P}$ value for normality (Pnorm) of residuals greater than 0.05 as yellow; $\mathrm{P}$ values less than the Bonferroni correction and Pnorm greater than 0.05 were labeled as red; $P$ values less than 0.005 but greater than Bonferroni correction and Pnorm greater than 0.05 were labeled orange. $\mathrm{P}$ values that were (1) less than 0.05 and greater than Bonferroni correction, (2) less than Bonferroni, (3) greater than Bonferroni, but all of which departed from the normality of the residuals, were labeled as blue green and beige, respectively. For the analysis presented here, we considered only the ESTs that fell in the color coding category of red, yellow and orange as differentially expressed across stages.

\section{RNA-DNA hybridization}

Total RNA $(30 \mu \mathrm{g})$, isolated from fruits of control, azygous and transgenic $556 \mathrm{HO}$ and $579 \mathrm{HO}$ lines at different stages of ripening as previously described ( $\mathrm{Li}$ et al. 1992), was electrophoresed on $1.2 \%$ agarose denaturing formaldehyde gels and blotted (Sambrook et al. 1989) on Hybond-N membrane (Amersham, UK). Hybridization was carried out with $[\alpha-$ ${ }^{32} \mathrm{P}$ ]dCTP $(3000 \mathrm{Ci} / \mathrm{mMol})$-labeled probe as indicated ( $\mathrm{Li}$ et al. 1992 ) at $42^{\circ} \mathrm{C}$ in $50 \%$ formamide, $5 \mathrm{X} \mathrm{SSC}, 50 \mathrm{mM}$ sodium phosphate, $\mathrm{pH} 6.8,0.1 \%$ sodium pyrophosphate, $0.1 \% \mathrm{SDS}, 5 \mathrm{X}$ Denhardt's solution and $50 \mu \mathrm{g} / \mathrm{ml}$ Herring sperm DNA (Sambrook et al. 2001). Each DNA probe was purified (Qiagen kit). Radiolabeling of cDNA inserts from different ESTs was carried out using a random primer labeling kit (DECA Prime II, Ambion, Austin, TX), which were then passed through Sephadex G-50 columns $(5.0 \mathrm{~cm} \times 1.0 \mathrm{~cm})$. After hybridization, membranes were washed twice for $15 \mathrm{~min}$ each in $2 \mathrm{X} \mathrm{SSC}$, $0.1 \% \mathrm{SDS}$ at $24^{\circ} \mathrm{C}$ and then twice for $10 \mathrm{~min}$ each in $0.2 \mathrm{X}$ $\mathrm{SSC}, 0.1 \% \mathrm{SDS}$ at $62^{\circ} \mathrm{C}$, and exposed to $\mathrm{x}$-ray films.

\section{Results}

\section{Higher polyamines affect gene expression in ripening fruits}

Tomato transgenic fruits overexpressing yeast SAMdc gene, $556 \mathrm{HO}$ and $579 \mathrm{HO}$ lines, show several phenotypes including improved juice attributes, higher ethylene production and increase in several primary and secondary metabolites (Mehta et al. 2002; Mattoo et al. 2006) indicating that endogenous increase in PAs results in significant changes in gene expression patterns. A comparison of transcript profiles between the fruit from azygous (556AZ) parental and the two transgenic, $556 \mathrm{HO}$ and $579 \mathrm{HO}$ lines of tomato was first ascertained by using cDNA subtraction cloning, sequencing and BLAST analysis. This screening resulted in isolation of $\sim 15$ cDNAs that represented genes from several different pathways including genes for LeSAMdc (PA biosynthesis), hsp17.6 (a chaperone protein), СуP (cyclophilin), ACO1 (ACC oxidase), LHCII (light harvesting chlorophyll $\mathrm{a} / \mathrm{b}$ binding protein), LeArcA1 (a $\beta$-subunit-like G protein), CDPK (calcium dependent protein kinase), and several genes not yet characterized. Northern analysis of selected cDNA was performed with total RNAs isolated from mature green $(\mathrm{G})$, breaker $(\mathrm{B})$, turning $(\mathrm{P})$ and red ripe $(\mathrm{R})$ fruit from transgenic and 556 azygous genotypes to establish the differential gene regulation by PAs (Figure 1). Among the transcripts that showed up-regulation, chaperone protein genes, TIP, Gprotein subunit, PME and lycopene cyclase were the predominant ones. LHCII gene transcripts were abundant at $\mathrm{G}$ and $\mathrm{B}$ stages in all the genotypes and their levels 


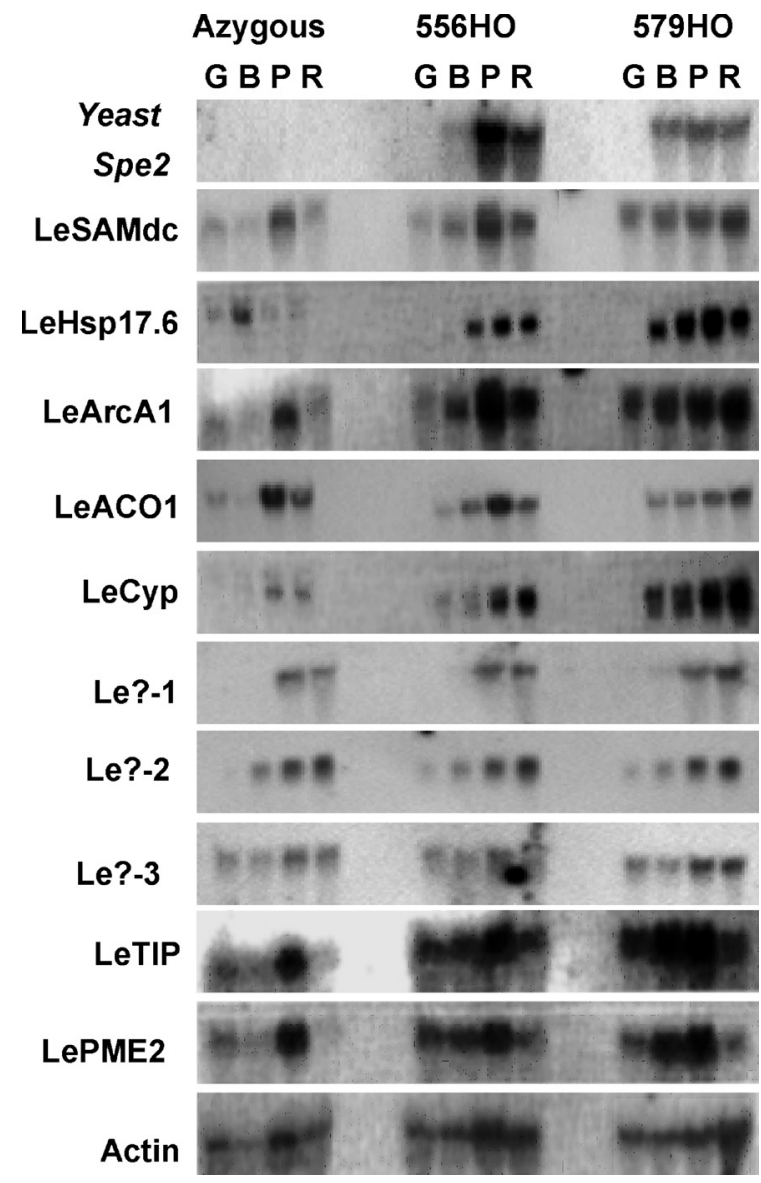

Figure 1. Polyamines regulate accumulation of specific gene transcripts. Changes in the levels of transcripts of genes cloned by subtractive cloning are shown during ripening of the azygous (566AZ) and two transgenic lines $(556 \mathrm{HO}$ and $579 \mathrm{HO})$ homozygous for the introduced SAM decarboxylase gene under the control of E8, a ripening specific promoter. In addition to the introduced transgene (Spe2, accession M38434) shown are the genes: LeSAMdc (accession S74514), LeHsp17.6 (accession AF123257), LeArcAI (accession AB022686), LeACO1 (accession X58273), LeCyp (accession M55019), and three novel genes Le?-1 (same as EST300801, accession Aw223990), Le?-2 (a tomato fruit-specific protein gene, accession X13743) and Le?-3 (same as EST262498, accession AI781619) whose nucleotide sequences did not match with sequences in databases. Also shown is the expression of LePME2 (accession U70675) and a tomato tonoplast intrinsic protein (similar to accession U86763). Normalization was carried out by hybridization to a radioactive actin probe. G, B, P and R represent fruits from mature green, breaker, pink and red ripe stages, respectively.

declined precipitously thereafter in all the genotypes (data not shown). The enhanced expression pattern of the indicated genes isolated by subtraction cloning occurred in parallel with the increases in $\mathrm{Spd} / \mathrm{Spm}$ especially in $\mathrm{P}$ and R stages of transgenic fruits (Mehta et al. 2002). These results suggested that the higher transcript levels of some of the identified cDNAs are a result of higher PA accumulation (Figure 1).

\section{Higher polyamines regulate expression of about one-quarter genes in ripening tomato fruits}

The above promising results led us to obtain a more global picture of gene expression using a custom-made tomato cDNA array since subtraction cloning is limited to the genes whose expression shows all or none expression patterns and thus a major proportion of the genes whose expression is differentially regulated in any two genotypes are missed. A tomato cDNA array was custom made at the Purdue genomic center from a normalized cDNA library made to poly $\mathrm{A}^{+}$RNA from the turning stage of tomato fruits and contains cDNA elements from 1066 unigenes and control ESTs including ESTs from pig that do not hybridize to tomato cDNA probes (Srivastava and Handa, unpublished results). The custom-made tomato cDNA array was employed to examine the effects of increased $\mathrm{Spd} / \mathrm{Spm}$ on gene expression in ripening fruits from wild-type and the 556HO transgenic fruits. Amongst 1066 unigene cDNAs present on this array, 710 displayed detectable and quantifiable signal intensities for the transgenic and the wild-type lines. Expression levels of the remaining were below the statistically detectable range from the non-hybridizing control spots. About $22 \%$ of these (154 ESTs) were found to be differentially expressed $(\mathrm{P}<0.05)$ in the transgenic compared to the control wildtype fruits (Table 1). Thirtyfive of the 154 ESTs showed highly significant differential expression as they met very stringent Bonferroni cut off $\left(7 \times 10^{-4}\right)$ and an FDR of 0.001435 (Benjamini and Hocheberg 1995). More than half of the differentially expressed genes (about 55\%) represented 10 functional categories, and the remaining $45 \%$ were novel, unknown or unclassified (Table 1). Results show that the effect of increased $\mathrm{Spd} / \mathrm{Spm}$ is uniform in almost all functional, novel, unclassified and unknown categories. It ranged between 17 to $28 \%$ of the unique ESTs present on the fruit-ripening gene array (Table 1). However, a higher percent of genes from the stress/defense and transcription categories showed over 2 -fold induction during ripening in the $\mathrm{Spd} / \mathrm{Spm}$ accumulating, transgenic ripe fruits. On the other hand, majority of the genes in the ethylene responsive and transport categories showed over 2-fold decrease during the ripening of transgenic fruits. We interpret these results to suggest that higher levels of $\mathrm{Spd} / \mathrm{Spm}$ cause a significant and marked shift in gene expression especially for genes involved in metabolism, energy, transcription and protein synthesis, signal transduction, and defense and stress responses in tomato fruit.

\section{Higher polyamines prevent down-regulation of tomato genes during fruit ripening}

Figure 2 depicts genes showing 2-fold higher or lower steady state transcript levels in transgenic fruit compared to the wild-type during ripening. In wild-type fruits, only 
Table 1. Distribution of unique ESTs on the tomato fruit array into functional categories and percent differentially expressed genes that are 2-fold up-or down-regulated in high $\mathrm{Spd} / \mathrm{Spm}$ transgenic fruit compared to parental wild-type fruit

\begin{tabular}{|c|c|c|c|c|c|c|}
\hline \multirow{2}{*}{ Classification } & \multicolumn{2}{|c|}{ Unique ESTs } & \multicolumn{2}{|c|}{$\begin{array}{l}\text { Differentially } \\
\text { Expressed ESTs }\end{array}$} & \multicolumn{2}{|c|}{$\begin{array}{l}\% \text { of differentially } \\
\text { expressed ESTs }\end{array}$} \\
\hline & Total no. & Detectable no. & no. & $\%$ detectable & $\begin{array}{l}2 \text {-fold } \\
\text { up-regulated }\end{array}$ & $\begin{array}{l}\text { 2-fold down } \\
\text { regulated }\end{array}$ \\
\hline $\begin{array}{l}\text { Cell structure and } \\
\text { maintenance }\end{array}$ & 16 & 9 & 0 & 0 & 0 & 0 \\
\hline Cell wall & 21 & 14 & 4 & 22 & 0 & 0 \\
\hline Defense/stress response & 61 & 48 & 13 & 28 & 54 & 8 \\
\hline $\begin{array}{l}\text { DNA replication repair } \\
\text { recombination }\end{array}$ & 11 & 9 & 2 & 22 & 0 & 0 \\
\hline Energy & 33 & 26 & 6 & 24 & 33 & 33 \\
\hline Ethylene response & 11 & 8 & 3 & 25 & 0 & 67 \\
\hline Metabolism & 117 & 85 & 22 & 26 & 36 & 9 \\
\hline $\begin{array}{l}\text { Protein } \\
\text { biosynthesis/degradation }\end{array}$ & 88 & 69 & 16 & 25 & 38 & 6 \\
\hline Signal transduction & 59 & 35 & 10 & 29 & 20 & 10 \\
\hline Transcription & 42 & 25 & 7 & 28 & 57 & 0 \\
\hline Transport & 44 & 27 & 6 & 23 & 0 & 67 \\
\hline Unclassified & 240 & 146 & 24 & 17 & 25 & 13 \\
\hline Unknown & 235 & 160 & 34 & 22 & 35 & 18 \\
\hline Novel & 88 & 49 & 10 & 21 & 10 & 10 \\
\hline Total & 1066 & 710 & 157 & & & \\
\hline
\end{tabular}

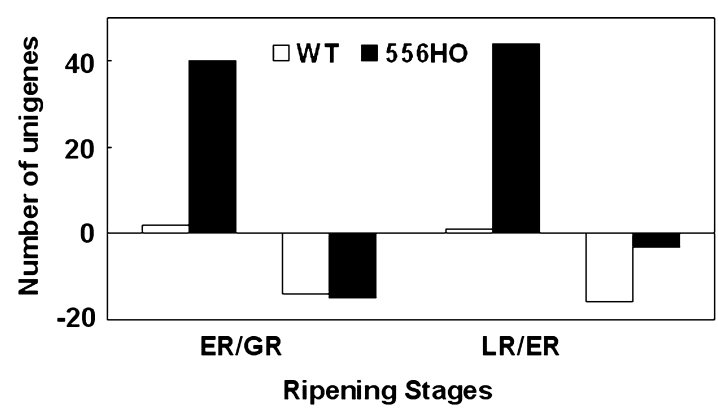

Figure 2. Genes up-and down-regulated between successive fruit ripening stages in high PA and wild-type fruits. Shown are number of genes up and down regulated (positive and negative values on y-axis, respectively) between green $(\mathrm{G})$ to early ripening (ER, Breaker to Breaker +3 days) and early ripening to late ripening (LR, Breaker $7 \mathrm{~d}$ to breaker 15d) stages in wild type (open bars) and 556HO (closed bars) based on analysis of arrays containing 1066 fruit unigene. The genes included are those that showed significant differential expression between wild-type and transgenic fruit and exhibited at least two-fold change in the transcript levels between the successive ripening stages. $\mathrm{G}$ to ER or ER to LR) stages of ripening. The positive and negative values on the $\mathrm{y}$ axis indicate up-and down-regulated unigenes, respectively.

a few genes showed up-regulation between green to early ripening (0-3d post $\mathrm{BR})$ and early ripening and late ripening ( $7-15 \mathrm{~d}$ post $\mathrm{BR})$ stages. On the other hand, in the $\mathrm{Spd} / \mathrm{Spm}$ fruits, transcript levels of 40 ESTs (35\% of the differentially expressed genes) and 44 ESTs (39\% of the differentially expressed genes) were over 2-fold higher between green to early ripening and early ripening and late ripening stages, respectively (Figure 2). Genes that were $>2$-fold down regulated were similar for wildtype (14 ESTs) and transgenic (15 ESTs) fruits between green to early ripening stages. However, only $3 \%$ of the genes were down regulated between early and late ripening in the transgenic compared to $13 \%$ in wild-type fruits. These results strongly indicate that $\mathrm{Spd} / \mathrm{Spm}$ prevent downward trend of gene expression normally observed during fruit ripening, which is consistent with their known role as anti-senescence effectors.

\section{Functional attributes of genes up-or down- regulated in high Spd/Spm fruits}

Genes expressed differentially between the high $\mathrm{Spd} / \mathrm{Spm}$ transgenic fruit compared to the parental wildtype using the DNA macroarray are listed in Tables 1-3. These ESTs encompass most of the functional categories with a large number yet to be functionally characterized and classified. Many of the genes have been isolated for the first time in our studies and thus have been designated as 'novel'. Over $54 \%$ of defense/stress response related and $57 \%$ of transcription related ESTs showed higher accumulation of their transcripts during ripening of $\mathrm{Spd} / \mathrm{Spm}$ tomatoes while only $8 \%$ of the stress/defense related and none of the transcription related ESTs showed a decline in their transcript levels during the same ripening period (Table 1). Similar patterns were observed for the ESTs related to metabolism and protein synthesis/degradation. Upregulated genes were four times as much those that were down regulated. This ratio was $6: 1$ for the protein synthesis and degradation related ESTs. The ratio of up and down regulated ESTs from the signal transduction category was 2:1 (Table 1). Only 8 ethylene response ESTs were present in the array and those showing at 
Table 2. Accession numbers and identity of genes showing up-regulation in the transgenic fruit at late ripening stages as compared to parental wild-type control fruit

\begin{tabular}{|c|c|}
\hline Accession & Identity \\
\hline \multicolumn{2}{|l|}{ Defense related } \\
\hline CD003445 & Hsp90 (17.6) \\
\hline CD003281 & Probable chaperonin 60 beta chain precursor, chloroplast \\
\hline CD003468 & Chaperonin CPN60-2, mitochondrial precursor (HSP60-2) \\
\hline CD002142 & SLT1 protein \\
\hline CD003207 & Metallothionein-like protein type 2 \\
\hline CD003053 & Heat shock cognate $70 \mathrm{kD}$ Protein \\
\hline CD002117 & $70 \mathrm{kD}$ peptidylprolyl isomerase \\
\hline CD002740 & Avr9/Cf-9 rapidly elicited protein 194 \\
\hline CD003093 & $70 \mathrm{kD}$ heat shock protein \\
\hline CD002613 & Glutathione S-transferase \\
\hline \multicolumn{2}{|l|}{ Metabolism related } \\
\hline CD002501 & Cinnamic acid 4-hydroxylase \\
\hline CD002405 & Lipoxygenase A \\
\hline CD002479 & CDP-alcohol phosphatidyltransferase family protein \\
\hline CD003193 & Flavonol synthase \\
\hline CD003247 & Phytoene synthase \\
\hline CD002285 & Alcohol oxidase related \\
\hline CD003472 & Mutant phytoene synthase \\
\hline CD003203 & S-adenosylmethionine decarboxylase \\
\hline CD002724 & Lipoxygenase $\mathrm{C}$ \\
\hline CD002862 & Similar to chalcone-flavonone isomerase \\
\hline CD003079 & Putative cytidine deaminase \\
\hline CD002917 & Putative pyruvate kinase \\
\hline CD002030 & Selenocysteine methyltransferase \\
\hline CD003316 & Putative amine oxidase \\
\hline CD002802 & 2-isopropylmalate synthase A \\
\hline CD002892 & dTDP-glucose 4-6-dehydratase-like protein \\
\hline CD002343 & Isopentenyl/dimethylallyl diphosphate synthase \\
\hline \multicolumn{2}{|r|}{ 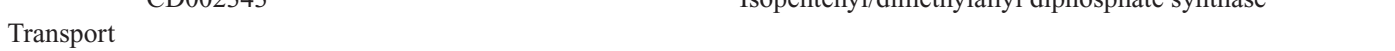 } \\
\hline CD002692 & Putative vesicle transport protein \\
\hline \multicolumn{2}{|l|}{ Transcription } \\
\hline CD002344 & Zinc finger (C3HC4-type RING finger) family \\
\hline CD002497 & Nuclear cap-binding protein CBP80 \\
\hline CD002126 & Putative small nuclear ribonucleoprotein E \\
\hline CD002910 & RING-finger protein \\
\hline CD002100 & $\mathrm{ABI} 3$-interacting protein $2, \mathrm{AIP} 2$ \\
\hline \multicolumn{2}{|c|}{ Protein biosynthesis and degradation } \\
\hline CD003399 & Putative N-myristoyl transferase \\
\hline CD002923 & Oligouridylate binding protein \\
\hline CN550628 & E2, ubiquitin-conjugating enzyme \\
\hline CD003016 & 60 S ribosomal protein $\mathrm{L} 4$ \\
\hline CD002897 & 50S ribosomal protein L15, chloroplast precursor \\
\hline CD002079 & Probable $26 \mathrm{~S}$ proteasome non-ATPase regulatory subunit 3 \\
\hline CD002957 & Chloroplast elongation factor \\
\hline CD002468 & Probable peptidylprolyl isomerase \\
\hline CD002803 & 40S Ribosomal protein S9 (S4) \\
\hline \multicolumn{2}{|l|}{ Energy/redox related } \\
\hline CD003254 & Cytochrome b5 \\
\hline CD002021 & Subunit A of ferredoxin-thioredoxin-reductase \\
\hline CD003414 & Thioredoxin $\mathrm{m} 2$ \\
\hline \multicolumn{2}{|l|}{ Signal transduction } \\
\hline CD002421 & Serine/threonine protein phosphatase PP2A \\
\hline CD002887 & Phytochrome B2 \\
\hline CD002796 & Putative phosphatidylinositol-4-phosphate 5-kinase \\
\hline CD003467 & ADP-ribosylation factor 1 \\
\hline CD002480 & PutativeGTP-binding protein \\
\hline CD003230 & LeArcA2 protein \\
\hline CD002295 & ADP-ribosylation factor 1 \\
\hline \multicolumn{2}{|l|}{ Ethylene response } \\
\hline $\mathrm{CD} 002173$ & 1-Aminocyclopropane-1-carboxylate oxidase homolog \\
\hline
\end{tabular}


Table 3. Accession numbers and identity of genes down-regulated in the high $\mathrm{Spd} / \mathrm{Spm}$ transgenic fruit at late ripening stage as compared to that from parental wild-type control

\begin{tabular}{|c|c|}
\hline Accession & Identity \\
\hline \multicolumn{2}{|l|}{ Defense related } \\
\hline CD002121 & Superoxide dismutase $[\mathrm{Cu}-\mathrm{Zn}]$, chloroplast precursor \\
\hline CD002708 & Pathogenesis-related protein STH-4 \\
\hline CD003004 & Lipid transfer protein 2 \\
\hline \multicolumn{2}{|l|}{ Metabolism related } \\
\hline CD002990 & Adenylosuccinate synthetase \\
\hline CD002753 & Expressed protein; protein id: At5g56260.1 \\
\hline CD002471 & Acetolactate synthase I, chloroplast precursor \\
\hline CD003273 & Putative dTDP-glucose 4-6-dehydratase \\
\hline CN550640 & Non-photosynthetic ferredoxin \\
\hline CD003100 & Photosystem II $10 \mathrm{KD}$ protein \\
\hline \multicolumn{2}{|l|}{ Transport } \\
\hline CD002573 & Hexose transporter \\
\hline CD002346 & Af10-protein \\
\hline CD002450 & Putative clathrin-associated protein \\
\hline CD003372 & Pto kinase interactor 1 \\
\hline \multicolumn{2}{|l|}{ Transcription } \\
\hline CD002586 & Zinc finger protein \\
\hline CD002210 & Putative zinc finger protein \\
\hline \multicolumn{2}{|c|}{ Protein biosynthesis and degradtion } \\
\hline CN550622 & CP12 protein, chloroplast precursor \\
\hline CD002846 & Cysteine proteinase inhibitor B \\
\hline CD003357 & Asparatic endopeptidase \\
\hline CD002141 & Methionine sulfoxide reductase domain containing protein \\
\hline CD002784 & RUB1 conjugating enzyme \\
\hline CD002422 & Ribosomal protein S19 \\
\hline \multicolumn{2}{|l|}{ Signal transduction } \\
\hline CD002435 & Kinase-like protein \\
\hline CD002762 & Putative leucine-rich repeat protein \\
\hline \multicolumn{2}{|l|}{ Ethylene response } \\
\hline CD003361 & Ethylene receptor \\
\hline
\end{tabular}

least 2-fold difference were mostly down regulated in the transgenic fruits. However, ACC oxidase 1 was 1.8-fold up-regulated, which is consistent with the results shown in Figure 1 with subtraction-derived genes. Although array contained 44 unique ESTs from the transport functional category, only a small number of them were differentially regulated between the wild-type and transgenic fruits (Tables 1-3). Among the unclassified and unknown categories, ratio of up and down regulated ESTs was $2: 1$. Ratio for the 'novel' ESTs was $1: 1$. Taken together these results support earlier observations that indicate involvement of higher endogenous PA levels in either up-regulating transcription or stabilizing transcripts for a large number of genes, which are representative of most of the functional categories.

\section{Expression patterns of differentially regulated ESTs}

Figure 3 shows the $\log _{2}$ expression ratio of transcript levels of ESTs in transgenic and wild-type fruits during fruit ripening from various 'functional' categories. Although levels and patterns of induction were somewhat unique for each up-regulated EST (Tables 2 and 3, Figure 3), higher accumulations of their transcripts were observed in red ripe fruits ( 7 to $15 \mathrm{~d}$ post
BR stage). Interestingly, many of the ESTs that were classified as down regulated (Table 3, Figure 3) also showed higher transcript levels in ripe fruit than at the earlier stages of fruit development and ripening. These patterns are consistent with the accumulation of $\mathrm{Spd} / \mathrm{Spm}$ late in ripening in transgenic fruits (Mehta et al. 2002) and the hypothesis that PAs generally have a stimulatory effect on the steady state levels of transcript.

\section{Effects of Spd/Spm on various functional classes of genes}

Among the defense/stress response related genes, a glutathione S-transferase like gene (CD002613) showed over 20-fold increase in the transgenic $556 \mathrm{HO}$ fruit compared to the wild-type. Other stress/defense related genes that were expressed in high abundance were SLT1 protein (CD002142), metallothionin-like protein type 2 (CD003207), HSP70 cognate (CD003053), peptidylprolyl isomerase (CD002117), Avr9/Cf-9 rapidly elicited protein 194 (CD002740) and 70kD HSP (CD003093). Notably, [Cu-Zn] superoxide dismutase (CD002121) exhibited about 10-fold reduction early during ripening of transgenic versus wild-type fruit (Figure 3). Among the metabolism related genes, isopentenyl/dimethylallyl diphosphate synthase 


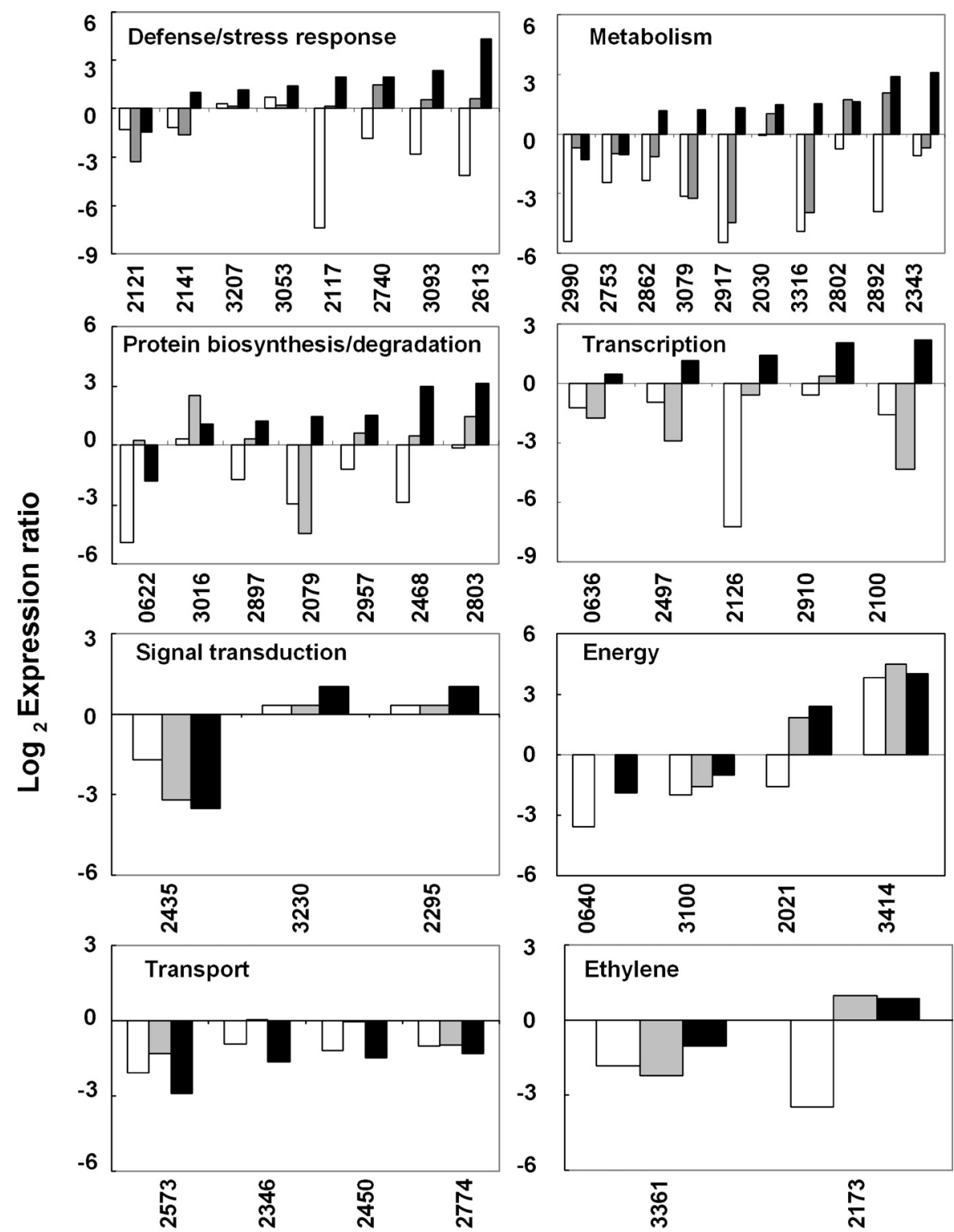

ESTs Accession number

Figure 3. Up-and down-regulated transcript levels of the differentially-expressed unigenes in high PA and wild-type fruits from different functional classes. Only genes that exhibited at least two-fold difference between the transgenic (556HO) and wild-type fruit at any ripening stage are included. Shown are the $\log _{2}$ of the ratio of transcript levels between transgenic and wild-type fruits at green (open bars), early ripening (gray bars) and fully ripened red (black bars) stages for the indicated unigene. Only the last 4 digits of accession numbers from Tables 2 and 3 are shown.

(CD002892) and dTDP-glucose 4-6-dehydratase-like protein (CD002343) were markedly up-regulated in the high $\mathrm{Spd} / \mathrm{Spm}$ transgenic fruit. Additionally, 2isopropylmalate synthase (CD002802), a putative amine oxidase (CD003316), selenocysteine methyltransferase (CD002030), a putative pyruvate kinase (CD002917), a putative cytidine deaminase (CD003079) and a putative chalcone-flavonone isomerase (CD002862) were over 2fold up-regulated in the transgenic fruit. The two ESTs CD002990 and CD002753 encoding an adenylosuccinate synthetase and a protein similar to At5g56260.1 were down regulated 2-fold (Figure 3 ).
Consistent with the anti-senescence attributes of PAs, several transcription and translation related genes were up regulated in transgenic fruits (Figure 3). Among the transcription related genes, ABI3-interacting protein 2 (CD002100) and a RING-finger protein (CD002910) were over 4-fold and a putative small nuclear ribonucleoprotein E (CD002126) and a nuclear capbinding protein CBP80 (CD002497) were over 2-fold up regulated in the transgenic fruit. Among the protein synthesis category, a 40S RIBOSOMAL PROTEIN S9 (CD002803) and a probable peptidylprolyl isomerase (CD002468) were considerably up regulated while 
several others including a chloroplast elongation factor (CD002957), a probable 26S proteasome non-ATPase regulatory subunit 3 (CD002079), 50S ribosomal protein L15 chloroplast precursor (CD002897) and 60S ribosomal protein L4 (CD003016) exhibited over 2-fold induction. None of the transcription related ESTs showed down regulation. However, CP12 protein, a chloroplast precursor (CN550622) did exhibit decrease in its transcripts levels in the transgenic fruit.

Thioredoxin $\mathrm{m} 2$ (CD003414), a redox and energy related EST, showed about 14 to 23 -fold increases in transcript levels throughout ripening of transgenic fruit whereas the subunit A of ferredoxin-thioredoxinreductase (CD00202) exhibited between 4-5-fold increase (Figure 3). However, photosystem II $10 \mathrm{kD}$ protein (CD003100) and non-photosynthetic ferredoxin (CN550640) showed more than 2-fold decrease in the ripening transgenic fruit (Figure 2E). ADP-ribosylation factor 1 (CD002295) and LeArcA2 (CD003230), two proteins implicated in signal transduction, showed at least 2-fold increase in their transcripts in transgenic fruits. Interestingly, a kinase-like protein (CD002435) exhibited over 10-fold reduction in the $\mathrm{Spd} / \mathrm{Spm}$ transgenic fruit (Figure 3).

Figure 3 shows the expression patterns of genes from the ethylene response and transport related ESTs. As stated earlier (Table 1), very few genes from the ethylene biosynthesis and action categories were represented in the array. Included among these was an ACC oxidase (CD002173) that was up regulated and an ethylene receptor like gene (CD003361) that was down regulated in transgenic fruits. Since most of the genes in ethylene biosynthesis and response in tomato are known, more work is needed to further characterize the effect of increased $\mathrm{Spd} / \mathrm{Spm}$ on these pathways. In the category of 'transport' most exhibited $\sim 2$ to 4 -fold reduction in the transgenic fruit.

Table 4 shows the expression patterns of ESTs for which homologous sequences have not been reported or which are not as yet functionally characterized. Patterns of these genes were also similar to those classified with biological functions, with most showing higher transcript levels in the late ripening stages. Transcript levels for some of these genes (for example, ESTs CD002619, CD003397, CD002983 and CD003373) were over 4-fold higher in transgenic compared to wild-type parental ripening fruit. Others (CD002552, CD002952 and CD002382) showed almost complete inhibition to over 100 -fold reduction in their transcripts in the ripe transgenic fruits. It will be of interest to identify these genes and to understand how and why PAs lead to a drastic reduction in their transcripts.
Table 4. Expression patterns of unknown, unclassified and novel differentially expressed unigenes

\begin{tabular}{|c|c|c|c|}
\hline \multirow{2}{*}{$\begin{array}{l}\text { Accession No./ } \\
\text { Ripening stage }\end{array}$} & \multicolumn{3}{|c|}{$\begin{array}{c}\log _{2} \text { of transgenic to wild-type } \\
\text { transcripts ratio }\end{array}$} \\
\hline & Green & Early Ripening & Late Ripening \\
\hline \multicolumn{4}{|l|}{ Unknown protein } \\
\hline CD002619 & -1.97 & -0.13 & 2.98 \\
\hline CD003397 & -2.86 & -1.50 & 2.56 \\
\hline CD002983 & -1.23 & -0.42 & 2.23 \\
\hline CD002202 & -4.32 & -0.88 & 1.71 \\
\hline CN550588 & -0.46 & 0.31 & 1.58 \\
\hline CD002308 & -3.30 & -2.29 & 1.52 \\
\hline CN550659 & -4.21 & -3.54 & 1.44 \\
\hline CD002852 & -2.42 & -0.64 & 1.39 \\
\hline CD003121 & -1.46 & -1.25 & 1.21 \\
\hline CD002446 & -4.01 & -0.99 & 1.16 \\
\hline CD003278 & -2.04 & -1.58 & 1.03 \\
\hline CN550592 & -2.69 & 1.16 & 1.01 \\
\hline CD002989 & -2.01 & 0.52 & -0.98 \\
\hline CD002866 & -6.17 & -2.72 & -1.21 \\
\hline CD002498 & -1.60 & -0.58 & -1.36 \\
\hline CD002953 & -4.02 & -3.47 & -1.75 \\
\hline CD003037 & -2.64 & -1.82 & -2.52 \\
\hline CD002382 & -2.51 & 0.05 & -4.09 \\
\hline CD002952 & -3.72 & -1.05 & -7.53 \\
\hline \multicolumn{4}{|c|}{ Unclassified protein } \\
\hline CD003373 & -3.14 & -1.06 & 2.25 \\
\hline CD002840 & -2.35 & 0.25 & 1.14 \\
\hline CD003258 & -1.63 & -3.49 & 1.14 \\
\hline CD002389 & -4.60 & -0.25 & 1.12 \\
\hline CD002868 & 0.86 & 0.89 & 1.07 \\
\hline CD002514 & -2.29 & -4.25 & 1.01 \\
\hline CD002596 & -1.78 & -1.09 & -1.00 \\
\hline CD002056 & -3.69 & -4.40 & -1.49 \\
\hline CD002552 & -2.08 & -4.39 & -8.13 \\
\hline \multicolumn{4}{|l|}{ Novel } \\
\hline CD002420 & -3.48 & -2.83 & 1.21 \\
\hline CD002494 & -0.79 & -1.19 & -1.22 \\
\hline
\end{tabular}

\section{Metabolite profiles of Spd/Spm tomatoes are consistent with effects on the transcriptome}

From the above results on $\mathrm{Spd} / \mathrm{Spm}$ modulated gene expression one can predict that a number of metabolic pathways are impacted. Interestingly, metabolite profiles of the $\mathrm{Spd} / \mathrm{Spm}$ accumulating transgenic fruit have indeed shown that metabolism of these fruit is considerably modulated as compared to that of the wildtype/azygous, control fruit (Mattoo et al. 2006). For instance, the pathways predicted by the metabolite profiles to be the targets of PA action include glycolysis, Krebs cycle, amino acid metabolism, lipid biosynthesis, and ethylene biosynthesis (Table 5). Therefore, PA mediated effects are coordinated at the transcriptional and posttranscriptional levels. Moreover, while some of the transcriptional changes are validated by parallel changes in the metabolite profiles, the latter also predict an impact on additional genes that are likely missing from the 1066 unigene macroarray used in this investigation. These predicted gene or protein targets of PA action include: invertase, asparagine and glutamine 
Table 5. Concurrence between metabolic pathways and genes affected in tomato fruit in response to higher endogenous spermidine and spermine

\begin{tabular}{|c|c|c|c|}
\hline Modulated Metabolite* & $+/-$ & Potential Gene Targets & Biochemical Pathway \\
\hline Sucrose & - & INVERTASE & Glycolysis/Transport \\
\hline Glucose & - & Hexose Transporter** & \\
\hline Asparagine & + & ASN SYNTHETASE, AMINOTRANSFERASES, & Amino acid biosynthesis \\
\hline Glutamine & + & GLN SYNTHETASE, GDEHYDROGENASE & Amino acid biosynthesis \\
\hline Citrate & + & Pyruvate kinase** & Krebs cycle \\
\hline Fumarate & + & Adenylosuccinate synthetase** & Krebs cycle \\
\hline Malate & + & MALIC ENZYME & Krebs cycle \\
\hline Lycopene & + & Phytoene synthase**, LYCOPENE CYCLASE & Carotenoid pathway \\
\hline Respiration & + & KREBS CYCLE ENZYMES & Krebs cycle \\
\hline Spermidine/Spermine & + & $\begin{array}{l}\text { S-adenosylmethionine decarboxylase**; } \\
\text { SPD/SPM SYNTHETASE }\end{array}$ & Polyamine biosynthesis \\
\hline Choline & + & $\begin{array}{l}\text { Phosphatidylinositol-4-phosphate kinase**; } \\
\text { Lipid transfer protein } 2^{* *} \text {; Selenocysteine } \\
\text { methyltransferase**, PHOSPHOLIPASES }\end{array}$ & Lipid metabolism; methylation reactions \\
\hline Ethylene & + & $\begin{array}{l}\text { 1-Aminocyclopropane-1-carboxylate oxidase homolog }{ }^{* *} \text {, } \\
\text { Ethylene receptor ETR } 5 * *\end{array}$ & $\begin{array}{l}\text { Ethylene biosynthesis and perception } \\
\text { perception }\end{array}$ \\
\hline FLAVONOIDS & $?$ & $\begin{array}{l}\text { Flavonol synthase/Chalcone } \\
\text { flavonone isomerase** (similar) }\end{array}$ & Flavonoid biosynthesis \\
\hline $\begin{array}{l}\text { LePEPC2 and } \\
\text { LeICDH transcript } \\
\text { levels }\end{array}$ & + & $\begin{array}{l}\text { AIP2, ring finger protein**, } \\
\text { nCBP } 80^{* *} \text {, } \\
\text { Ser/thr protein phosphatase** }\end{array}$ & Transcription \\
\hline
\end{tabular}

* Metabolites that were up (+) or down (-) regulated in ripening transgenic compared to wild type fruit (Mattoo et al, 2006)

$* *$ Based on transcriptome analysis (present investigation).

Uppercase letters: Predictions not yet validated

synthetases, aminotransferases, malic enzyme, $\mathrm{Spd} / \mathrm{Spm}$ synthetases, phospholipases, methylation reactions, and key enzymes in the Krebs cycle. Flavonoids and nitrogen-sensing metabolites are among the metabolites that are predicted to be increased in the high PA transgenic fruit because of the transcriptional changes (Table 5).

\section{Discussion}

We present molecular analysis of tomato fruits engineered to accumulate higher PAs, Spd and Spm, and demonstrate that PAs act as anabolic growth regulators. This is illustrated in Figure 4 by the vast number of anabolic pathways that are impacted in the high $\mathrm{Spd} / \mathrm{Spm}$ transgenic fruit. By overexpressing yeast SAMdc under the control of a ripening regulated promoter E8 we have generated a tomato genotype in which $\mathrm{Spd} / \mathrm{Spm}$ increase by 3 -to 4 fold during ripening of the fruits. This is in contrast to the wild type or azygous fruits in which the levels of both Spd and Spm decline during ripening (Mehta et al., 2002). This model system was used to address the role of PAs in tomato fruit metabolism. Subtractive cloning provided the first evidence that the increased $\mathrm{Spd} / \mathrm{Spm}$ in the SAMdc transgenic genotypes results in regulation of several gene transcripts including those that represent the following functional groups: chaperone family (LeHsp 17.6 and cyclophilin LeCyP), signal transduction (G protein, LeArcA1), fruit ripening (ACC oxidase, LeACO1; ethylene receptor Etr5; LeSAMdc), vacuolar function (LeTIP), and cell wall metabolism (pectinmethylesterase, LePME). Four other unknown genes were also isolated. These data were further confirmed and a more global picture of changes in the transcriptome of the PA-accumulating fruit obtained by using a custom made array of over 1,000 unique tomato cDNAs. About $25 \%$ of the total genes present on the cDNA array are differentially regulated in the transgenic fruit. The genes whose expression increased in the transgenic fruit during ripening belong to a wide range of functional categories, some of these already unveiled by the subtractive cloning as described above: transcription, translation, signal transduction, chaperone family, stress related, amino acid biosynthesis, ethylene biosynthesis and action, PA biosynthesis, isoprenoid biosynthesis, carotenoids and flavonoid biosynthesis. Additionally, a number of cDNA whose encoded products are yet to be classified for functional attributes were isolated. Among the down-regulated genes in the transgenic compared to the wild-type included genes involved in transport and ethylene signaling. These global changes in the transcript accumulation are likely a result of transcriptional activity; however, it is yet to be determined whether increased levels of PAs also affect the stability of specific gene transcripts. Our conclusion that PAs act as anabolic growth regulators is further supported by data on metabolite profiles of the transgenic fruit versus the wild type/azygous controls. The pathways involved in the nitrogen sensing/signaling and carbon metabolism are preferentially activated in the high $\mathrm{Spd} / \mathrm{Spm}$ transgenics. We suggest that higher PAs are perceived as nitrogenous 


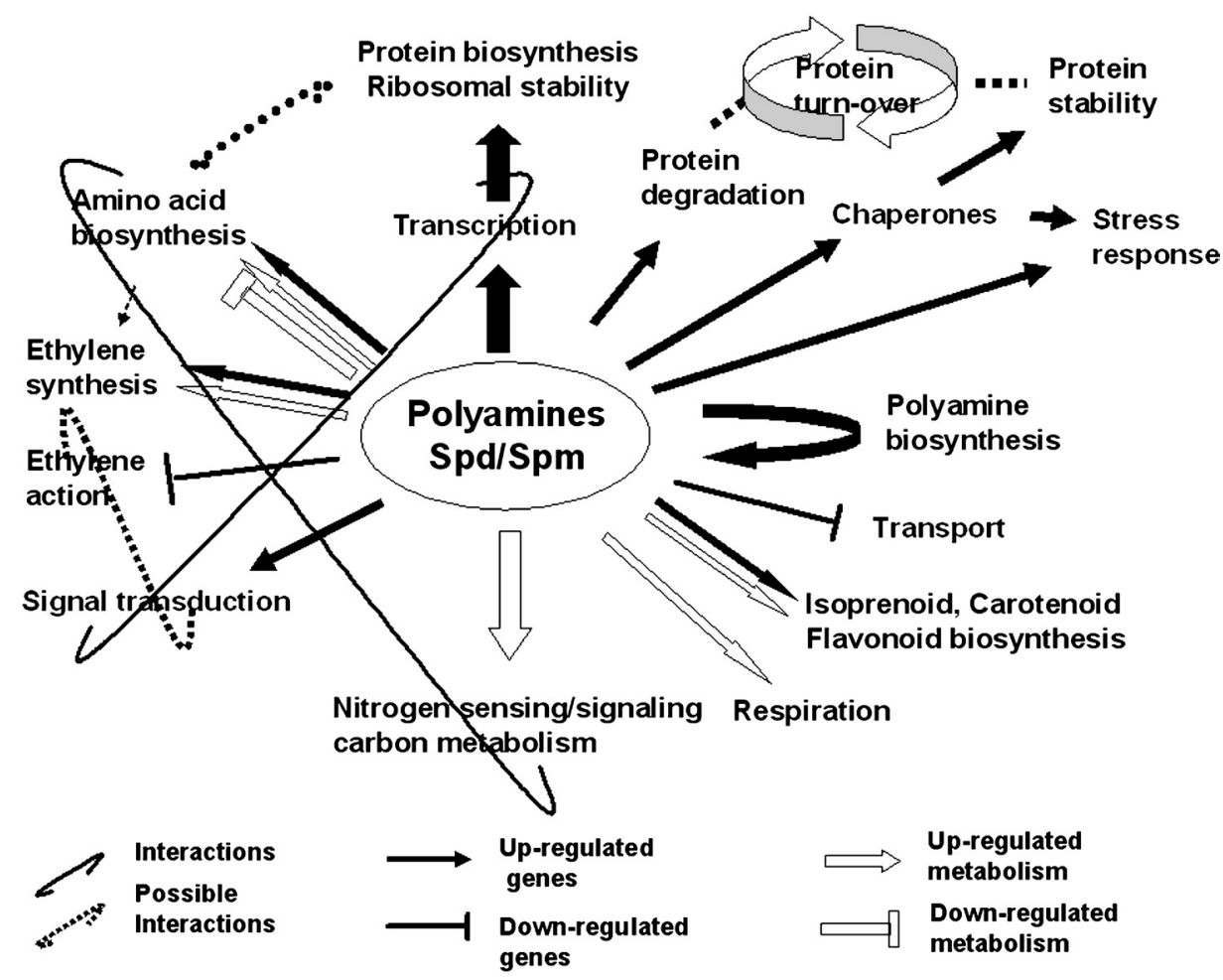

Figure 4. Polyamine regulated metabolic pathways and other processes in ripening tomato fruits. Concurrence between regulated genes (this study; filled arrows) and metabolite profiles (Mehta et al. 2002, Mattoo et al. 2006; open arrows). In addition, signaling and interdependent interactions are indicated that likely are a result of cross-talk between different processes mediated by Spd and Spm.

metabolites by the fruit cells, which in turn causes the stimulation of carbon sequestration (Mattoo et al., 2006). The transgenic fruits show increased respiration during fruit ripening which is accompanied by upregulation of phosphoenolpyruvate carboxylase and NADP-dependent isocitrate dehydrogenase transcripts in the transgenic compared to controls fruits (Mattoo et al. 2006), indicating that PAs enhance metabolic status of the transgenics even late in fruit ripening. Taken together these results provide strong evidence that PAs enhance metabolic status, especially the anabolic metabolism in fruit cells, which may play significant roles in maintaining homeostasis in the ripening fruits.

The observed changes in the cellular metabolism in the transgenic tomato fruit are obviously not a result of a single mode of action. However, it is clear that transcription/translation of a number of genes is coordinated with $\mathrm{Spd} / \mathrm{Spm}$-mediated changes in the metabolite profiles in the transgenic tomato fruit, suggesting that activation and sustenance of transcription is one means by which $\mathrm{Spd} / \mathrm{Spm}$ regulate fruit metabolism. In animal cells, higher PAs regulate transcription by acting as a switch between different coactivators without altering the state of the chromatin (Maeda et al. 2002) or by affecting histone acetylation/deacetylation (Hobbs and Gilmour 2000). Also, a posttranscriptional role for PAs has been shown in down-regulating animal genes ( $\mathrm{Li}$ et al. 2001) while a certain group of Escherichia coli genes is controlled by the diamine putrescine at the translational level (Yoshida et al. 2004). In the latter case, it was suggested that putrescine enhances transcription of a group of genes by increasing the level of transcription factors. PA-mediated modulation of protein synthesis may involve, among other things, structural changes in RNA, stimulation of 30S ribosomal assembly, tRNA formation (Igarashi and Kashiwagi 2000) or a frameshift during translation into protein which is dependent on a Shine-Dalgarno-like sequence in E. coli (Higashi et al. 2006). Regulation of gene expression by PAs can also occur via an effect on the structure of eIF5A or oligomerization of nucleosomal arrays (Childs et al. 2003). It is of interest to note here that the levels of eIF5A transcripts increase during tomato fruit ripening and the introduction of the yeast SAMdc transgene has no effect on this increase $(\mathrm{S}-\mathrm{H}$. Chung and A.K. Mattoo, unpublished data).

One of the mechanisms of PA-mediated effects on transcription leading to protein synthesis involves binding of trans-acting factors to PA-responsive, ciselement (PRE) identified in human $\mathrm{Spd} / \mathrm{Spm} \mathrm{N}^{1}$ acetyltransferase (SSAT) gene (Chen et al. 1997; Wang et al. 1998, 2001). The sequence 5'-TATGACTAA-3' represents the PRE in human SSAT. Since we found that a substantial number of genes are modulated in the tomato fruit engineered to accumulate $\mathrm{Spd} / \mathrm{Spm}$ in a ripening-specific manner, we looked for PRE sequences 
in some of the candidate, up-regulated fruit genes. Our preliminary analysis indicated the presence of similar but not identical PRE's in only a few genes, including the lipoxygenase (LOX) gene (B. Karakas and A.K. Mattoo, unpublished data), which is up-regulated in the higher PA accumulating transgenic tomatoes. Further, we have found that tomato fruit contain nuclear proteins that are able to retard the mobility of a LOX sequence harboring a putative PRE using gel-shift assays (B. Karakas and A.K. Mattoo, unpublished data). These data together with the transcriptome analysis and the metabolite profiles support a role of transcriptional activators for $\mathrm{Spd} / \mathrm{Spm}$ in plants.

\section{Acknowledgments}

This study was partly supported by a US-Israel BARD grant to AKH and AKM (Grant N0. IS-3441-03) and a grant from the U.S. Department of Agriculture, IFAFS program (Award No. 741740) to AKH. Mention of trade names or commercial products in this publication is solely for the purpose of providing specific information and does not imply recommendation or endorsement by the U.S. Department of Agriculture.

\section{References}

Benjamini Y, Hocheberg Y (1995) Controlling the false discovery rate: a practical and powerful approach to multiple testing. $J$ Royal Stat Soc 57: 289-300

Biggs MS, Handa AK (1989) Temporal regulation of polygalacturonase gene expression in fruits from normal mutant and heterozygous tomato genotypes. Plant Physiol 89: $117-125$

Cassol T, Mattoo AK (2003) Do polyamines and ethylene interact to regulate plant growth, development and senescence? In: Nath P, Mattoo AK, Ranade SR, Weil JH (eds) Molecular Insights in Plant Biology. Science Publishers, Inc., Enfield, USA, pp 121-132

Chen TT, Wu RL, Castro-Munozledo F, Sun TT (1997) Regulation of K3 keratin gene transcription by $\mathrm{Sp} 1$ and AP-2 in differentiating rabbit corneal epithelial cells. Mol Cell Biol 17: 3056-3064

Childs AC, Mehta DJ, Gerner EW (2003) Polyamine-dependent gene expression. Cell Mol Life Sci 60: 1394-1406

Cohen SS (1998) A guide to polyamines. Oxford Uni. Press, New York

DeScenzo RA, Minocha SC (1993) Modulation of cellular polyamines in tobacco by transfer and expression of mouse ornithine decarboxylase cDNA. Plant Mol Biol 22: 113-127

Egea-Cortines M, Mizrahi Y (1991) Polyamines in cell division, fruit set and development, and seed germination. In: Slocum RD, Flores HE (eds) Biochemistry and Physiology of Polyamines in Plants. CRC Press, Boca Raton, FL, pp 143-158

Fluhr R, Mattoo AK (1996) Ethylene-biosynthesis and perception. Crit Rev Plant Sci 15: 479-523

Galston AW, Sawheny RK (1990) Polyamines in plant physiology. Plant Physiol 94: 406-410

Giovannoni J (2004) Genetic regulation of fruit development and ripening. Plant Cell 16: S170-S180
Hamill JD, Robins RJ, Parr AJ, Evans DM, Furze JM, Rhodes MJC (1990) Over-expression a yeast ornithine decarboxylase gene in transgenic roots of Nicotiana rustica can lead to enhanced nicotine accumulation. Plant Mol Biol 15: 27-83

Higashi K, Kashiwagi K, Taniguchi S, Terui Y, Yamamoto K, Ishihama A, Igarashi K (2006) Enhancement of +1 frameshift by polyamines during translation of polypeptide release factor 2 in Escherichia coli. J Biol Chem 281: 9527-9537

Hobbs CA, Gilmour SK (2000) High levels of intracellular polyamines promote histone acetyltransferase activity resulting in chromatin hyperacetylation. J Cell Biochem 77: 345-360

Igarashi K, Kashiwagi K (2000) Polyamines: mysterious modulators of cellular functions. Biochem Biophys Res Commun 271: 559-564

Kasukabe Y, He L, Nada K, Tachibana S (2004) Overexression of spermidine synthase enhances tolerance to multiple environmental stresses and up-regulates the expression of various stress regulated genes in transgenic Arabidopsis thaliana. Plant Cell Physiol 45: 712-722

Kumar A, Taylor MA, Mad-Arif SA, Davies H (1996) Potato plants expressing antisense and sense S-adenosylmethionine decarboxylase (SAMDC) transgenes show altered levels of polyamine and ethylene: antisense plants display abnormal phenotypes. Plant J 9: 147-158

Li L, Rao JN, Guo X, Liu L, Santora R, Bass BL, Wang J-Y (2001) Polyamine depletion stabilizes p53 resulting in inhibition of normal intestinal epithelial cell proliferation. Am J Physiol Cell Physiol 281: C941-C953

Li N, Parsons BL, Liu DR, Mattoo AK (1992) Accumulation of wound-inducible ACC synthase transcript in tomato fruit is inhibited by salicylic acid and polyamines. Plant Mol Biol 18: 477-487

Maeda Y, Rachez C, Hawel III L, Byus CV, Freedman LP, Sladek FM (2002) Polyamines modulate the interaction between nuclear receptors and DRIP205. Mol Endocrinol 16: 1502-1510

Mattoo AK, Handa AK (2004) Ethylene signaling in plant cell death. In: Nooden L (ed) Plant Cell Death Processes. Academic Press, New York, pp 125-142

Mattoo AK, Sobolev AP, Neelam A, Goyal RK, Handa AK, Segre AL (2006) NMR spectroscopy based metabolite profiling of transgenic tomato fruit engineered to accumulate spermidine and spermine reveals enhanced anabolic and nitrogen-carbon interactions. Plant Physiol

Mehta RA, Cassol T, Li N, Ali N, Handa AK, Mattoo AK (2002) Engineered polyamine accumulation in tomato enhances phytonutrient content, juice quality, and vine life. Nature Biotechnol 20: 613-618

Noh EW, Minocha SC (1994) Expression of human Sadenosylmethionine decarboxylase cDNA in transgenic tobacco and its effects on polyamine biosynthesis. Transgenic Res 3: 26-35

Ozga JA, Reinecke DM (2003) Hormonal interactions in fruit development. J Plant Growth Regul 22: 73-81

Rafart-Pedros A, MacLeod MR, Ross HA, McRae D, Tiburcio AF, Davies HV, Taylor MA (1999) Manipulation of Sadenosylmethionine decarboxylase activity in potato tubers. Planta 209: 153-160

Ramakrishna W, Deng Z, Ding CK, Handa AK, Ozminkowski RH Jr (2003) A novel small heat shock protein gene, vis1, contributes to pectin depolymerization and juice viscosity in tomato fruit. Plant Physiol 131: 725-735

Ross JJ, O'Neill DP (2001) New interactions between classical 
plant hormones. Trends Plant Sci 6: 2-4

Sambrook J, Fritsch EF, Maniatis T (1989) Molecular Cloning: A Laboratory Manual 2nd ed. Cold Spring Harbor: Cold Spring Harbor Laboratory Press.

Singh AK, McIntyre LM., Sherman LA (2003) Microarray analysis of the genome-wide response to iron deficiency and iron reconstitution in the Cyanobacterium Synechocystis sp. PCC 6803. Plant Physiol 132: 1825-1839

Srivastava A, Handa AK (2005) Hormonal regulation of tomato fruit development: A molecular perspective. J Plant Growth Reg 24: 67-82

Takahashi N, Ko MSH (1994) Toward a whole cDNA catalog: construction of an equalized cDNA library from mouse embryos. Genomics 23: 202-210

Walden R, Cordeiro A, Tiburcio AF (1997) Polyamines: small molecules triggering pathways in plant growth and development. Plant Physiol 113: 1009-1013

Wang Y, Xiao L, Thiagalingam A, Nelkin BD, Casero Jr RA
(1998) The identification of a cis-element and a trans-acting factor involved in the response to polyamines and polyamine analogues in the regulation of the human spermidine/spermine $\mathrm{N}^{\prime}$-acetyltransferase gene transcription. J Biol Chem 273: 34623-34630

Wang Y, Devereux W, Stewart TM, Casero Jr RA (2001) Characterization of the interaction between the transcription factors human polyamine modulated factor (PMF-1) and NFE2related factor 2 (Nrf-2) in the transcriptional regulation of the spermidine/spermine $\mathrm{N}^{\prime}$-acetyltransferase (SSAT) gene. Biochem J 355: 45-49

Watson MB, Malmberg R (1998) Arginine decarboxylase (polyamine synthesis) mutants of Arabidopsis thaliana exhibit altered root growth. Plant J 13: 231-239

Yoshida M, Kashiwagi K, Shigemasa A, Taniguchi S, Yamamoto K, Makinoshima H, Ishihama A, Igarashi K (2004) A unifying model for the role of polyamines in bacterial cell growth, the polyamine modulon. J Biol Chem 279: 46008-46013 